\title{
Association Between the Predictors of Functional Capacity and Heart Rate Off-Kinetics in Patients with Chronic Obstructive Pulmonary Disease
}

This article was published in the following Dove Press journal: International Journal of Chronic Obstructive Pulmonary Disease

\author{
Patrícia Faria Camargo (D) \\ Luciana Ditomaso- \\ Luporini (iD) ' \\ Luiz Carlos Soares \\ de Carvalho Jr (iD ${ }^{2}$ \\ Cássia da Luz Goulart (iD) \\ Rayane Sebold (iD) 1,3 \\ Polliana Batista dos Santos (iD) \\ Meliza Goi Roscani iD 4 \\ Audrey Borghi-Silva (D) \\ 'Cardiopulmonary Physiotherapy \\ Laboratory, Physiotherapy Department, \\ Federal University of Sao Carlos, Sao Paulo, \\ Brazil; ${ }^{2}$ Center for Science and Technology \\ in Energy and Sustainability of Federal \\ University of Reconcavo da Bahia, Feira de \\ Santana, Bahia, Brazil; ${ }^{3}$ Course of \\ Physiotherapy, Central Paulista University \\ Center, Sao Carlos, Sao Paulo, Brazil; \\ ${ }^{4}$ Medicine Department, Federal University \\ of Sao Carlos, Sao Carlos, Sao Paulo, Brazil
}

Correspondence: Audrey Borghi-Silva Email audrey@ufscar.br
Background: The heart rate (HR) kinetics as well as other predictors of functional capacity such as the Chronic Obstructive Pulmonary Disease (COPD) Assessment Test (CAT), the Duke Activity Status Index (DASI) and the handgrip strength (HGS) represent important tools in assessing the impact of COPD on exercise performance and health status of individuals with COPD.

Purpose: To verify the relationship between functional capacity, measured using the sixminute walking test (6MWT), with the HR off-kinetics, HGS and the DASI and CAT scores. Methods: For this cross-sectional study, 29 subjects with COPD underwent body composition, pulmonary function and cardiac function tests. Subsequently, the DASI and CAT questionnaires and HGS test were performed. The beat-to-beat R-R intervals (IRR) were collected in rest, during the test and in recovery after the 6MWT. The HR off-kinetics was obtained during a 360 -second period in post-exercise recovery through the HR mono-exponential decay.

Results: Moderate correlations were observed between: 1) walked distance (WD) in the 6MWT and the CAT and DASI scores $(\mathrm{r}=-0.58, \mathrm{p}=0.001$ and $\mathrm{r}=0.58, \mathrm{p}=0.001$, respectively); 2) WD and HGS ( $\mathrm{r}=0.37, \mathrm{p}=0.05) ; 3)$ and WD and HR off-kinetics $(\tau ; \mathrm{r}=-0.54$, $\mathrm{p}=0.002$ and MRT; $\mathrm{r}=-0.55, \mathrm{p}=0.002$, respectively).

Conclusion: The 6MWT performance is a direct measurement to evaluate functional capacity. Additionally, it is related to other direct and indirect markers for functional evaluation in patients with COPD. These results suggest the application of these tools in clinical practice, based on the accessibility, non-invasive character and easy applicability of these methods.

Keywords: COPD, questionnaires, exercise, kinetics

\section{Introduction}

Characterized by a progressive airflow limitation, the chronic obstructive pulmonary disease (COPD) ${ }^{1}$ involves important extrapulmonary manifestations that imply in quality of life impairments. ${ }^{2}$ Additionally, these limitations are also associated with more exacerbations and hospitalizations, accentuation of effort intolerance and are related to low survival rates. ${ }^{3}$ The exercise intolerance leads to a sedentary lifestyle which culminates in a progressive decline in functional capacity. ${ }^{4,5}$

In this sense, functional capacity assessment through exercise tolerance evaluation is valuable in patients with COPD because it offers information that could aid in the differential diagnosis, disease progression and intervention response monitoring, prognosis, and prediction of mortality, ${ }^{6}$ and may be evaluated in direct 
measurements such as six-minute walking test (6MWT) and handgrip strength (HGS) - widely used, validated and low-cost methods. ${ }^{7-10}$

The indirect measurements such as specific questionnaires may be complementary tools whenever the application of field tests is impracticable. ${ }^{1-13}$ The Duke Activity Status Index (DASI) is a brief, quick and simple questionnaire, capable of predicting oxygen consumption $\left(\dot{\mathrm{VO}}_{2}\right)$. This questionnaire does not require the application of a maximal cardiopulmonary exercise test, which is a highcost, space-demanding, involves an operational team and specialized equipment - most commonly found in research laboratories. $^{14}$ Likewise, the COPD Assessment Test (CAT) is a short questionnaire that quantifies the impact of symptoms in patients with COPD. Additionally, the CAT is useful to evaluate the individuals' health status, as well as the impact of exercise intolerance in daily routine, well-being and general health of these patients ${ }^{1}$ and described an appliance that can be estimating the $\mathrm{VO}_{2}$ peak. $^{15}$

Besides the high correlation with mortality predictors in patients with COPD such as the BODE, ${ }^{16}$ the $6 \mathrm{MWT}$ also enables the evaluation of functional capacity, symptoms, as well as, cardiovascular variables that are also considered to be important to predict functional capacity. ${ }^{16-19}$ The post-exercise heart rate (HR) recovery (off-kinetics) has been recognized as a predictor factor for exacerbation and mortality in multiple respiratory diseases (ie, COPD), and it is straightly related to functional capacity and quality of life. ${ }^{20}$ Additionally, the HR off-transient reflects changes in cardiac autonomic modulation to manage the energy requirements during the post-exercise recovery, remarked by a gradual restoration of the parasympathetic activity. ${ }^{21}$ A slowed response of the HR recovery at the end of the exercise corresponds to a reduced influence of the parasympathetic modulation on the sinoatrial node, representing higher probabilities of adverse cardiovascular outcomes. ${ }^{20,22,23}$

Individuals with COPD become more inactive when compared to the elderly, and this inactivity directly affects functional capacity. ${ }^{24}$ In addition to its relationship with health status, physical deconditioning and increased risk for cardiovascular events. ${ }^{16,20}$ Hence, the analysis of HR off-kinetics has become an interesting and practical tool to assess cardiovascular integrity. However, it is still unknown the degree of correlation between the direct and indirect measurements and the HR kinetics during recovery after the 6MWT in individuals with COPD. In this sense, we hypothesized that these individuals would present a diminished functional capacity, as well as slowed cardiac responses, which consequently contributes to the occurrence of comorbidities and increased cardiovascular risk followed by sudden death. Thus, the aim of the study was to identify whether there is a relationship between functional capacity, obtained through the 6MWT, and HR kinetics, evaluated using direct and indirect measures for the functional assessment.

\section{Methods}

\section{Study Design}

This transversal study included men and women with COPD, aged $\geq 50$ years in the city of Sao Carlos/SP. For recruitment, medical records were actively searched in the Pneumology Outpatient Clinic of the Center of Medical Specialties (CEME) of Sao Carlos, in the Health-School Unit (USE) and in previous studies carried out in the Cardiopulmonary Physiotherapy Laboratory (LACAP) of the Federal University of Sao Carlos (UFSCar), between July 2017 and July 2019. After medical records evaluation, the invitations to participate in the study were made by phone call. Their participation was conditioned to a period of disease stability (at least 3 months from the last exacerbation) and optimized medication use before starting the assessments. Participants were not included in the study if they refused to participate, did not answer phone calls, inaccurate phone information and deaths.

Exclusion criteria involved use of home oxygen therapy, diabetes mellitus, uncontrolled arterial and pulmonary hypertension; history of cardiac arrhythmias and potential alterations in the electrocardiogram; neurological and orthopedic conditions that precluded the performance of the required protocol. The study followed the Declaration of Helsinki and was approved by the Ethics and Research Committee of the Federal University of Sao Carlos, Sao Paulo, Brazil (CAAE $n^{\circ}$ 2.597.588) approved the study. All participants were informed about the objectives, experimental procedures and potential risks involved in trial and signed a consent form before the beginning of the study.

\section{Experimental Procedures}

Assessments were performed in two separate days, in which the first day was composed of clinical assessments, body composition, pulmonary function test (for diagnostic confirmation and disease staging), echocardiogram (for 
exclusion criteria ratification), questionnaires and HGS On the second day, subjects performed the functional capacity test.

\section{First Assessment Day}

Anamnesis and physical exam were performed to obtain information about general health status, drugs currently used and anthropometric measurements of the individuals. The evaluation of body composition was made by the measurement of stature using a stadiometer (Welmy R-110, Santa Barbara d'Oeste, Sao Paulo, Brazil). Individuals were positioned in the center of the equipment, standing upright, barefoot, arms extended at the side of the body and head facing forward at a right angle to the neck. The body mass and body mass index were obtained through bioelectrical impedance (InBody ${ }^{\circledR} 720$, Biospace Co. Ltd, Seoul, Korea), following the same positioning and orientations previously described. Additionally, subjects were instructed to wear light clothing and to fast for at least 4 hours. ${ }^{25}$

The pulmonary function test was evaluated using spirometry $\left(\mathrm{CPFS} / \mathrm{D}^{\circledR}\right.$ Medgraphic, MGC Diagnostics Corporation, St. Paul, MN, USA), performed by a previously trained researcher, which used conventional techniques and followed the technical recommendations, of acceptability and reproducibility from the American Thoracic and European Respiratory Societies (ATS/ERS). ${ }^{26}$ At least three slow, forced, acceptable and reproducible maneuvers were performed and repeated 20 minutes after the inhalation of Salbutamol Sulfate $(400 \mu \mathrm{g})$.

The echocardiogram applied to exclude any individual with heart failure was performed using the equipment Philips HD11 (Bothell Everett Highway; Bothell, WA, USA) carried out by a specialist physician which followed the American Society of Echocardiography. ${ }^{27}$ Patients were evaluated in left lateral decubitus and individuals that presented left ventricle ejection fraction $<50 \%$ were excluded.

The Portuguese versions of the questionnaires employed in the study were previously validated and were applied for a trained professional. ${ }^{28,29}$ The CAT is composed of eight items (cough, phlegm, chest tightness, breathlessness, limited activities, confidence leaving home, sleeplessness and energy) purposed to evaluate and quantify the impact of symptoms in patients with COPD. The patients with COPD are classified into mild (6-10), moderate (11-20), severe (21-30) and very severe (31-40). ${ }^{1}$ Regarding the DASI, the higher the scoring (maximal score: 58.2), the higher the estimated $\dot{\mathrm{V}}_{2}$, which represents a better physical fitness. ${ }^{14}$
The HGS (kgf) was evaluated using a hydraulic dynamometer (Jamar Jackson, MI 49,203, USA). Patients should be seated, elbows flexed at $90^{\circ}$, forearm and wrist in neutral position, according to the American Society of Hand Therapists recommendations. Three voluntary contractions, split by $60 \mathrm{~s}$ of rest, were performed with the dominant upper limb. ${ }^{30,31}$

\section{Second Assessment Day}

For the 6MWT, subjects were instructed and encouraged (ie, standardized verbal encouragement) to walk the longest possible distance in 6 minutes on a 30-meter long and flat corridor, previously demarked by a colored tape. It was emphasized that in case of necessity, the participant could interrupt the test at any moment. The test was performed two times 30 minutes apart, according to the American Thoracic Society ${ }^{32}$ recommendations, and the best performance (ie, the largest walked distance covered [WD]) was selected for the analysis. Prior to each test, two periods of 4 minutes in seated rest and then in orthostatic position were respected. The registry of the best performance (WD in meters), as well as the occurrence and duration of the pauses during walking and desaturation $>4 \%$ were made at the peak of the exercise. After exercising, a 6-minute rest was considered.

The HR (Polar S810 ${ }^{\circledR}$, Kempele, Oulu, Finland) and the systemic arterial pressure (Sphygmomanometer BIC ${ }^{\circledR}$, Itupeva, Sao Paulo) were measured using the auscultatory method (stethoscope Littman ${ }^{\circledR}$ Classic II, USA). The peripheral oxygen saturation $\left(\mathrm{SpO}_{2}\right)$, measured using a digital oximeter (Nonin ${ }^{\circledR}$, modelo 2500, Minneapolis, MN, USA), and the modified BORG CR-10 rated-perceived scale ${ }^{33}$ were monitored and registered in the pre-test rest, at peak exercise and in the first, third and sixth minutes of recovery.

\section{Heart Rate Off-Kinetics Analysis}

The HR off-kinetics data were firstly extracted from the cardio-frequency meter by using the software Polar ProTrainer ${ }^{\circledR} 5$. Following, after visual inspection to verify the signal quality and the constant characteristic of the test, with the steady-state HR responses profile between $60 \%$ and $85 \%$ of the maximal HR, predicted for each participant. ${ }^{34}$ The exponential modeling was performed using a specific routine developed in the software CardioKin 1.2, according to the parameters calculated by a certified LabVIEW-associated developer (LabVIEW 
2012, National Instruments, Austin, TX, USA), which follows the pattern of Levenberg-Marquardt. ${ }^{35}$

A monoexponential modeling was used for the postexercise recovery phase (360 seconds), $f_{(t)}=a_{0}+A(1-e$ $\left.{ }^{(\mathrm{t}-\mathrm{TD}) /} \tau\right)$, where $\mathrm{f}_{(\mathrm{t})}$ represents HR at any moment, $\mathrm{a}_{0}$ represents the baseline value corresponding to the mean HR of the last minute of exercise, A (bpm) is the amplitude of the steady-state HR responses, $\tau$ represents the exponential time constant (s), which must reach $63 \%$ of the steadystate response (ie, HR adaptation), and TD (s) represents the time delay to the beginning of the HR response. The mean response time (MRT) was calculated as the sum of $\tau$ and TD for the general kinetic evaluation ${ }^{36}$ and the signal quality, assured by analysis of residues. ${ }^{37}$

Tests were excluded from the analysis if they presented an incremental characteristic or pauses during the exercise.

\section{Study Outcomes}

The primary outcomes of the study were the functional performance during the 6MWT and the HR off-kinetics (transition from the exercise to recovery). The secondary outcomes were the associations between the WD and the HGS, the DASI score, the CAT score and the behavior of cardiovascular variables during recovery after the 6MWT.

\section{Statistical Analysis}

The sample size calculation was made using the software GPower 3.1 (Kiel University, Kiel, Germany), considering a correlation of 0.5 for the effect size; $\alpha=0.05$; sample power of $85 \%$. The calculus indicated a sample size of 29 subjects.

The software used for statistical analysis were the Statistical Package for Social Science version 20 (SPSS Inc., Chicago, IL, USA) e Graphpad Prism 8 (GraphPadPrism, La Jolla, California). The normality of data was verified using the Shapiro-Wilk test, expressed as mean and 95\% confidence interval (IC 95\%). Following, Pearson and Spearman correlation tests were applied according to the nature of the distribution of the data for the HR off-kinetics $\left(\mathrm{a}_{0}, \mathrm{~A}, \mathrm{TD}, \tau, \mathrm{MRT}\right)$, the HGS and the CAT and DASI scores. The magnitude of correlations was determined considering the following classification scheme for $\mathrm{r}$ values: $\leq 0.35$ low or weak; $0.36 \leq 0.67$ moderate; $\geq 0.68$ strong or high; $\geq 0.9$ very high; and perfect: 1 . $^{38}$

There were excluded from the analysis all individuals that presented pauses and interruptions during the 6MWT or did not reach $60 \%$ to $85 \%$ of the maximal HR during the exercise.

The level of significance adopted was $5 \%$.

\section{Results}

Overall, 146 individuals from the Pneumology Outpatient Clinic of the CEME of Sao Carlos and the Health-School Unit (UFSCar) were screened, in which 89 were not eligible for the study. From the remaining 56 individuals, 10 were excluded for 6MWT interruption due to decline in $\mathrm{SpO}_{2}$ $(>4 \%)$. These individuals were classified as: 1 (10\%), Global Initiative for Chronic Obstructive Lung Disease (GOLD) I; 2 (20\%), GOLD II; and 7 (70\%), GOLD III. These individuals presented pauses of approximately 1.1 \pm 0.3 minutes during the walking period, with mean duration of $1.65 \pm 0.9$ minutes. All participants returned to exercise after this period.

Only one individual required oxygen supplementation $(1 \mathrm{~L} / \mathrm{min})$ during the pause and continued its use until the end of the post-test recovery, being excluded from the final sample. Six individuals were excluded for not reaching the minimal intensity of $60 \%$ of maximal HR; two for presenting incremental pattern of exercise; and eight for poor cardio-frequency meter signal quality, which precluded analysis. None of the individuals presented any signal of intolerance to exercise. The final sample was composed of 29 individuals (Figure 1).

Table 1 shows the demographic, anthropometric and spirometric characteristics, and functional capacity of the patients with COPD, which was predominantly composed of men. Five patients (17.2\%) were classified as mild COPD (GOLD I), $15(51.7 \%)$ as moderate COPD (GOLD II), nine (31\%) as severe COPD (GOLD III) and one $(3.4 \%)$ as very severe COPD (GOLD IV).

Figure 2 displays the correlations between symptomatology, functional capacity and HR off-kinetics. Moderate negative correlations were found between functional capacity (WD and DASI) and symptomatology, referred by the CAT questionnaire; moderate positive correlations were found between functional capacity (WD) and DASI questionnaire, and between functional capacity and HGS. Likewise, there were moderate negative correlations between functional capacity (DC) and $\tau$, and between functional capacity and MRT $(r=-0.54$ and $\mathrm{p}=0.002 ; \mathrm{r}=-0.55$ and $\mathrm{p}=0.002$, respectively). Table 2 presents the functional capacity results, obtained through 6MWT, and the HR offkinetics parameters of the individuals with COPD.

\section{Discussion}

Our aims were to verify the association between functional capacity, obtained through the 6MWT, and HR off-kinetics, 


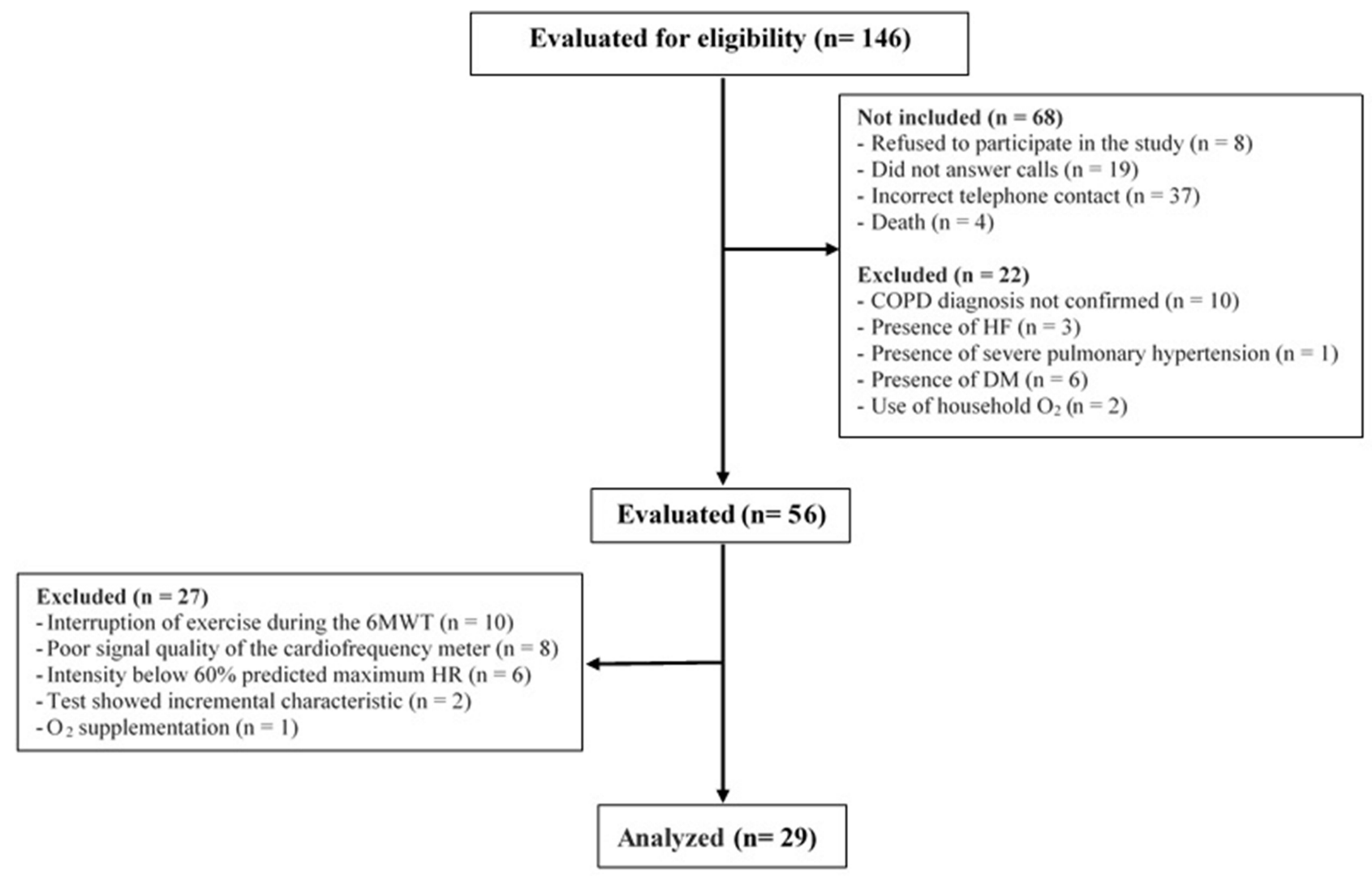

Figure I Flowchart of screening and study participants.

Abbreviations: COPD, chronic obstructive pulmonary disease; HF, heart failure; DM, diabetes mellitus; $\mathrm{O}_{2}$, oxygen; 6MWT, six-minute walk test; HR, heart rate.

measured using direct and indirect measures for the functional assessment of patients with COPD. The main findings were: 1) moderate negative association between functional test performance and symptomatology, referred by the CAT and the level of physical activity, indirectly obtained through the DASI; 2) moderate positive association between functional capacity measured using the HGS and the DC; 3) negative correlations between HR off-kinetics and the DC.

The previous studies indicate that the peripheral muscle dysfunction and bioenergetic abnormalities in skeletal muscle are related to functional capacity and symptomatology during exercise. ${ }^{39-41}$ In accordance, once our findings demonstrated that the larger the symptomatology, the lower the WD and the physical fitness (Figure 2), the presence of dyspnea is related to alterations in the respiratory, cardiovascular and neuromuscular systems. ${ }^{42}$

Besides the measurement of functional capacity, the WD is capable of predicting a larger number of exacerbation episodes and mortality risk among the individuals with $\mathrm{COPD}^{43,44}$ that cover $<350$ meters in the $6 \mathrm{MWT}^{43}$
However, this value cannot be applied to the Brazilian population once it presents a higher functional performance when compared to international populations. ${ }^{4,45,46}$ In this sense, since the Brazilian population lacks a representative parameter, it has been considered that the functional capacity is classified as satisfactory in case the individual covers $80 \%$ of the ideally estimated WD. ${ }^{43}$ The percentage of WD in the 6MWT reflects the individual's performance in relation to the studied population, enabling a higher control of biases regarding the absolute value. In the present study, patients presented $\sim 91 \%$ of $\mathrm{WD}$, as well as a good level of physical activity according to the DASI score (35 [30-40]), thus indicating a satisfactory functional capacity. ${ }^{47,48}$ This performance might be related to a higher percentage of individuals with mild and moderate degrees of disease ( $\sim 83 \%$ of the total sample).

The dyspnea presented in COPD restricts the individuals from performing the activities of daily living and evokes the adoption of a sedentary lifestyle, which consequently induces declines in muscle mass and strength ${ }^{9,49-}$ 
Table I Baseline Patient Characteristics

\begin{tabular}{|l|l|}
\hline Variables & COPD (n=29) \\
\hline Demographic and anthropometric & $21(72)$ \\
Male $n(\%)$ & $66(63.32-69.03)$ \\
Age (years) & $69.8(62.98-76.70)$ \\
Body Mass (kg) & $1.67(163.73-169.79)$ \\
Height (m) & $25.2(23.2-27.2)$ \\
BMI (kg/m2) & \\
\hline Pulmonary function & $1.58(1.30-1.86)$ \\
FEVI (L) & $56.9(49.64-64.21)$ \\
FEVI (\%) & $2.90(2.54-3.25)$ \\
FVC (L) & $82.5(75.72-82.39)$ \\
FVC (\%) & $0.53(0.49-0.57)$ \\
FEVI/FCV & $5 / 15 / 9 / 1$ \\
GOLD (I/ II/ III/IV) & $12(3-28)$ \\
CAT & \\
\hline Echocardiography & $32.8(30.2-35.4)$ \\
RV (mm) & $69.6(65.6-73.6)$ \\
EF (\%) & \\
\hline Therapies & $12(41.4 \%)$ \\
SABA n (\%) & $13(44.8 \%)$ \\
LABA n (\%) & $10(34.5 \%)$ \\
LAMA n (\%) & $3(10.3 \%)$ \\
Inhalation corticoide $\mathrm{n}(\%)$ & $14(48.3)$ \\
ACE inhibitor. $\mathrm{n}(\%)$ & $6(20.7 \%)$ \\
Beta-blocker $\mathrm{n}(\%)$ & $9(31 \%)$ \\
Others $\mathrm{n}(\%)$ & \\
\hline
\end{tabular}

Note: Data expressed as mean and $95 \%$ confidence interval $(95 \% \mathrm{Cl})$ and interquartile range (25-75\%).

Abbreviations: COPD, chronic obstructive pulmonary disease; BMI, body mass index; $\mathrm{FEV}_{\mathrm{l}}$, forced expiratory volume in the first second; FVC, forced vital capacity; $\mathrm{FEV}_{\mathrm{l}} / \mathrm{FVC}$, ratio of forced expiratory volume in the first second to forced vital capacity; CAT, COPD Assessment Test; RV, right ventricle diameter; EF, ejection fraction; SABA, short-acting beta-2-agonist; LABA, long-acting beta-2-agonist; LAMA, long-acting anticholinergic; ACE inhibitor, angiotensin-converting enzyme inhibitor.

52 as demonstrated by the individuals in this study by through the HGS ( 30 kgf, displayed in Table 2). Moreover, studies have demonstrated a strong correlation between HGS and muscle volume and strength of upper and lower limbs. ${ }^{53}$ Additionally, HGS has been also associated with functional capacity in individuals with COPD and inversely associated with mortality risk. ${ }^{10,54,55}$

Interestingly, our study found a moderate correlation between the different instruments that assess functional capacity by different metabolic pathways and even considering subjectivity intrinsic to the DASI. Despite the three tools - 6MWT, HGS and DASI questionnaire evaluate functional capacity, there are differences between these methods. The 6MWT and HGS are direct measures, and the latter represents an indirect measure, and therefore, subjectively evaluate such outcome. The 6MWT is a dynamic exercise testing that enables a global evaluation of the cardiorespiratory, muscular and metabolic systems and involves the oxidative bioenergetic system, characterized by the higher recruitment of slow-twitch fibers (type I). ${ }^{56}$ The HGS evaluates the isometric contraction strength of the upper limb that comprises the activation of a lower quantity of muscles and involves the glycolytic energy system, which is predominantly composed of type II fibers. ${ }^{31}$ On the other hand, the DASI indirectly evaluates $\mathrm{VO}_{2}$ by a questionnaire related to activities of daily living, involving the individual's perception and self-report. ${ }^{14}$

Regarding the HR off-kinetics, Vasilopoulou et al (2012) used a non-invasive method to investigate the MRT, cardiac debt and systolic volume of HR in the beginning, during a constant-load displacement exercise and in the 6MWT in patients with different levels and severity degrees of COPD. The authors found MRToff values of $\sim 41 \mathrm{~s}, \sim 48 \mathrm{~s}, \sim 69 \mathrm{~s}$ e $\sim 93 \mathrm{~s}$, for mild, moderate, severe and very severe degrees of COPD, respectively, in which each group represented $25 \%$ of the total sample. Despite the absence of stratification by severity, our sample was predominantly composed by moderate COPD $(51.7 \%)$, with mean MRT of $\sim 72 \mathrm{~s}$, which presented to be similar to the subgroup severe $(\sim 69 \mathrm{~s})$ noted in Vasilopoulou et al (2012) and emphasizes the higher cardiovascular impairment of our sample. The presence of dynamic hyperinflation during the exercise imposes negative cardiovascular effects such as diastolic dysfunction, which implies in worse results during and after exercise and may assist the understanding of the presented behavior; ${ }^{16,19,23}$ however, this condition was not evaluated in our study. Thus, it is suggested that future studies address the relation between the dynamic hyperinflation and the HR kinetics during post-exercise recovery.

Pessoa et al also found delayed kinetic responses related to $\dot{\mathrm{VO}}_{2}$ in individuals with COPD (higher $\tau$ and MRT values) when compared to control group. These findings were justified by the severity of the airflow obstruction and functional capacity limitation. However, these results were observed in a cycle ergometer and during the exercise phase, differently from our study, that evaluated the recovery after the 6MWT.

Comparing the means of $\tau$ and MRT presented in our study with the values described by Simões et al for healthy older adults (55s vs $\sim 30 \mathrm{~s}$ and $73 \mathrm{~s}$ vs $\sim 40 \mathrm{~s}$, for $\tau$ and MRT, respectively), it is inferred that our sample presented greater impairment in the responses of such variables. 
A

$\mathbf{A}$

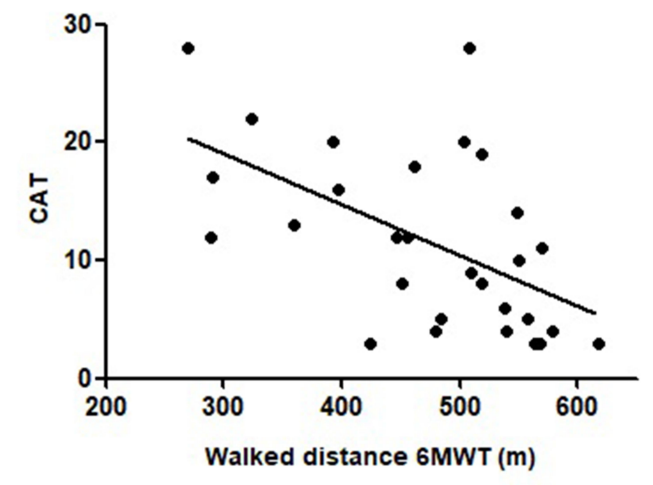

C

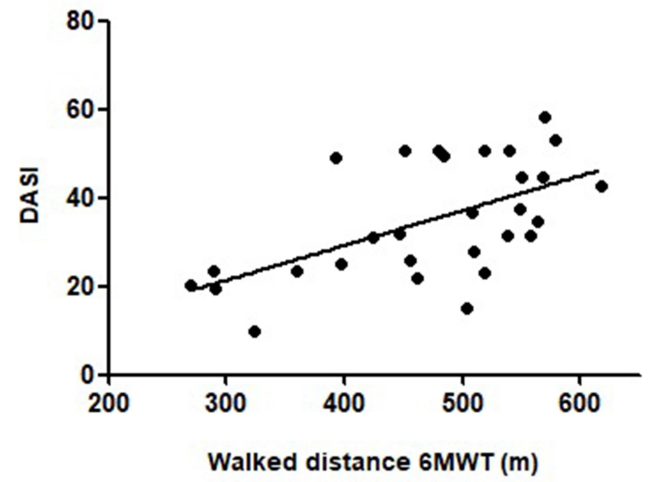

E

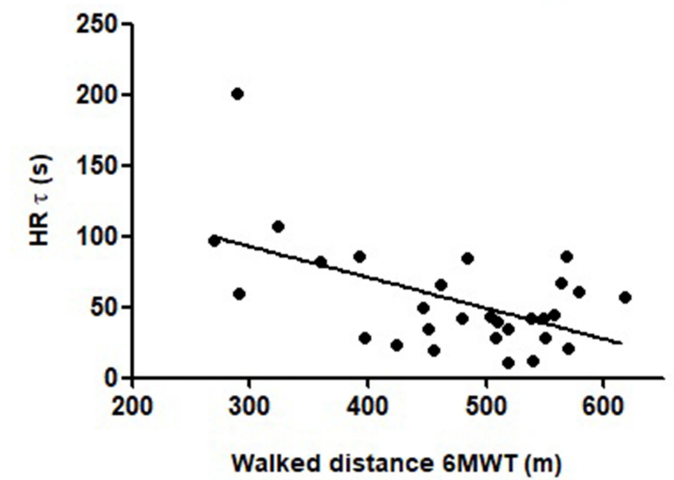

B

$r=-0.58$

$p=0.0009$

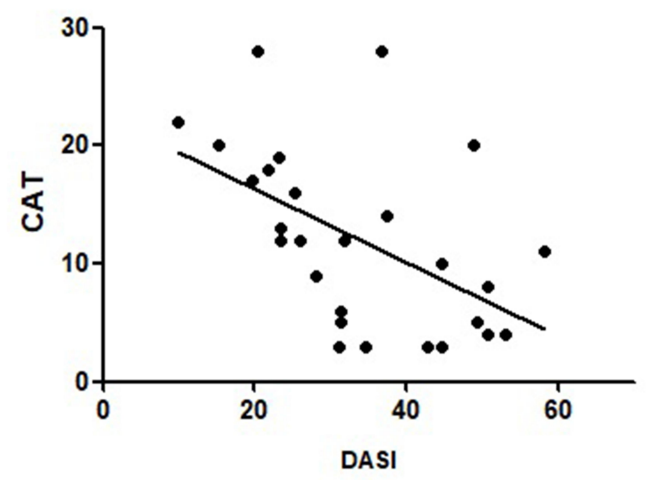

D

$r=0.37$

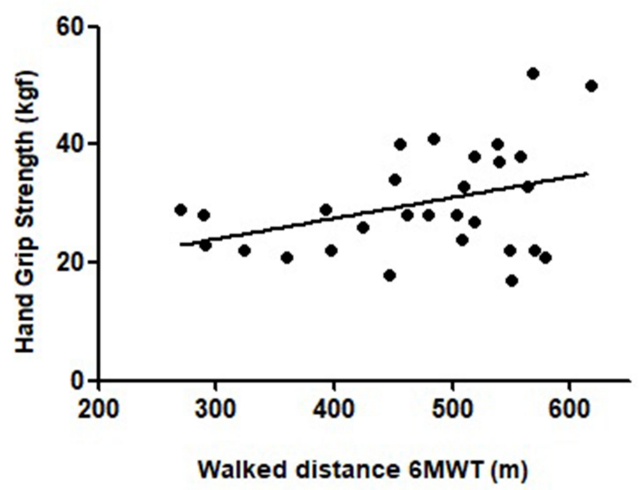

F

$r=-0.55$

$p=0.002$

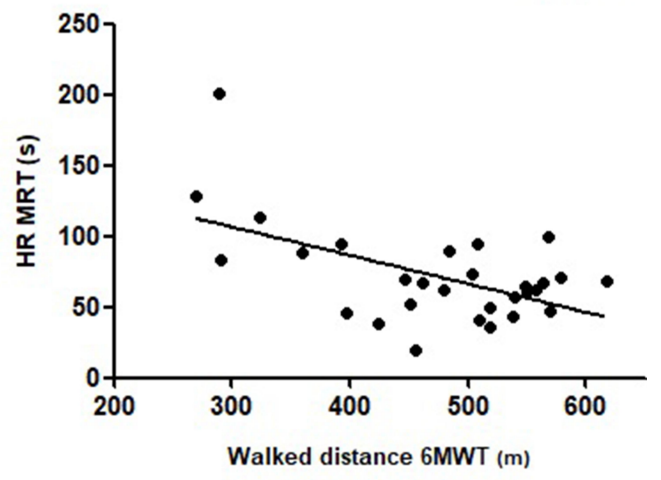

Figure 2 Correlation between functional capacity in the six-minute walk test and: (A, B) the symptoms referred by the CAT; (C) DASI; (D) the handgrip strength test; (E) the time constant of heart-rate recovery kinetics and $(\mathbf{F})$ the mean response time of heart-rate recovery kinetics. 
Table 2 Functional capacity and kinetic responses of heart rate on the recovery phase of the 6MWT

\begin{tabular}{|l|l|}
\hline Variables & COPD (n=29) \\
\hline Functional Capacity & \\
DASI & $35(30-40)$ \\
HGS (kgf) & $30(26.6-33.5)$ \\
6MWT (WD, m) & $473(436.82-509.29)$ \\
6MWT (\%predict) & $91(84.33-98.56)$ \\
\hline Kinetic off HR & \\
a0 (bpm) & $110(105.01-115.02)$ \\
A (bpm) & $28(23.89-32.55)$ \\
TD (s) & $18(10.83-22.74)$ \\
$\tau(s)$ & $55(40.62-69.65)$ \\
MRT (s) & $72(58.67-85.18)$ \\
\hline
\end{tabular}

Note: Data expressed as mean and confidence interval $(95 \% \mathrm{Cl})$.

Abbreviations: DASI, Duke Activity Status Index; HGS, handgrip strength; 6MWT, six-minute walk test; $a_{0}$, baseline value corresponding to the $H R$ value of the final minute of the exercise period; A, amplitude of the magnitude of the steadystate heart-rate response; TD, time delay for the start of the HR response; $\tau$, exponential time constant; MRT, mean response time.

Possibly, to our findings, the impairments in the cardiac autonomic modulation caused by the COPD were added to the effects of ageing, favoring the delay in HR recovery responses. In this sense, Bonança et $\mathrm{al}^{57}$ demonstrated that $\tau$ and MRT were larger in patients with COPD with associated heart failure (HF-COPD) when compared to individuals that presented only heart failure (HF). This fact emphasizes that the lower ventilatory efficiency presented by HF-COPD patients results in worse $\mathrm{VO}_{2}$ off-kinetics.

The present study presents some limitations to be considered. The low number of individuals among different GOLD classification does not allow, at the time, that the results are generalized for the COPD population, whereas that individuals with lighter severities are usually asymptomatic and with a little participation in health and rehabilitation services. In addition, due to this element of the sample, it was not possible to point out, by these estimates, which are the most serious and are the main responders when compared to other illness severities. However, we emphasize the relevance of the study, considering the simplicity, practicality, low cost and agreement of the different functional capacity assessment instruments. However, future studies are needed to understand and evaluate the influence of lung function, as well as, the referred symptoms of the disease, on the heart-rate recovery behavior in the different GOLD classifications, in addition to allowing, with the monitoring over time of these variables, greater support for the rehabilitation programs of these individuals.

\section{Conclusion}

The 6MWT performance is directly associated with other strong, direct and indirect, predictors of functional capacity. Additionally, the 6MWT is inversely associated with the HR off-kinetics in individuals with COPD. These findings demonstrate that simple, direct and indirect tools may be useful for functional evaluation whenever the application of field tests is impracticable.

\section{Author Contributions}

All authors made substantial contributions to conception and design, acquisition of data, or analysis and interpretation of data; took part in drafting the article or revising it critically for important intellectual content; and agree to be accountable for all aspects of the work.

\section{Funding}

Grants from the Federal University of Sao Carlos/FAPESP process numbers: 2015/26501-1 and 2018/00860-3.

\section{Disclosure}

The authors report no conflicts of interest in this work.

\section{References}

1. Patel AR, Patel AR, Singh S, Singh S, Khawaja I. Global initiative for chronic obstructive lung disease: the changes made. Cureus. 2019. doi: $10.7759 /$ cureus. 4985

2. Guenette JA, Chin RC, Cheng S, et al. Mechanisms of exercise intolerance in global initiative for chronic obstructive lung disease grade 1 COPD. Eur Respir J. 2014;44(5):1177-1187. doi:10.1183/ 09031936.00034714

3. Kim HC, Lee GD, Hwang YS. Skeletal muscle dysfunction in patients with chronic obstructive pulmonary disease. Tuberc Respir Dis (Seoul). 2010;68(3):125-139. doi:10.4046/trd.2010.68.3.125

4. Pitta F, Troosters T, Spruit MA, Probst VS, Decramer M, Gosselink R. Characteristics of physical activities in daily life in chronic obstructive pulmonary disease. Am J Respir Crit Care Med. 2005;171(9):972-977. doi:10.1164/rccm.200407-855OC

5. Haave E, Hyland ME, Skumlien S. The relation between measures of health status and quality of life in COPD. Chron Respir Dis. 2006;3 (4):195-199. doi:10.1177/1479972306070069

6. Laukkanen J, Kurl S, Salonen R, Rauramaa R, Salonen J. The predictive value of cardiorespiratory fitness for cardiovascular events in men with various risk profiles: a prospective population-based cohort study. Eur Heart J. 2004;25(16):1428-1437. doi:10.1016/j.ehj.2004.06.013

7. Enright PL, McBurnie MA, Bittner V, et al. The 6-min walk test: a quick measure of functional status in elderly adults. Chest. 2003;123(2):387-398. doi:10.1378/chest.123.2.387

8. Polkey MI, Spruit MA, Edwards LD, et al. Six-minute-walk test in chronic obstructive pulmonary disease: minimal clinically important difference for death or hospitalization. Am J Respir Crit Care Med. 2013;187(4):382-386. doi:10.1164/rccm.201209-1596OC

9. Felipe C, Bartolome C, Miguel D, Victor -P-P. Longitudinal changes in handgrip strength, hyperinflation, and 6-minute walk distance in patients with COPD and a control group. Chest. 2015;148 (4):986-994. doi:10.1378/chest.14-2878 
10. Burtin C, Ter Riet G, Puhan MA, et al. Handgrip weakness and mortality risk in COPD: a multicentre analysis. Thorax. 2016;71 (1):86-87. doi:10.1136/thoraxjnl-2015-207451

11. Schutz Y, Weinsier RL, Hunter GR. Assessment of free-living physical activity in humans: an overview of currently available and proposed new measures. Obes Res. 2001;9(6):368-379. doi:10. 1038/oby. 2001.48

12. Pitta F, Troosters T, Probst VS, Spruit MA, Decramer M, Gosselink R. Quantifying physical activity in daily life with questionnaires and motion sensors in COPD. Eur Respir J. 2006;27 (5):1040-1055. doi:10.1183/09031936.06.00064105

13. Vilaró J, Resqueti V, Fregonezi G. Avaliação clínica da capacidade do exercício em pacientes com doença pulmonar obstrutiva crônica. Rev Bras Fisioter. 2008;12(4):249-259. doi:10.1590/S1413-355520080004 00002

14. Hlatky MA, Boineau RE, Higginbotham MB, et al. A brief self-administered questionnaire to determine functional capacity (the duke activity status index). Am J Cardiol. 1989;64(10):651-654. doi:10.1016/0002-9149(89)90496-7

15. Carvalho LCS Jr, Trimer R, Arêas G, et al. COPD assessment test and FEV1: do they predict oxygen uptake in COPD? Int J Chron Obstruct Pulmon Dis. 2018;13:3149-3156. doi:10.2147/COPD. S167369

16. Borghi-Silva A, Beltrame T, Reis MS, et al. Relationship between oxygen consumption kinetics and BODE index in COPD patients. Int J COPD. 2012;7:711-718. doi:10.2147/COPD.S35637

17. Vasilopoulou MK, Vogiatzis I, Nasis I, et al. On- and off-exercise kinetics of cardiac output in response to cycling and walking in COPD patients with GOLD stages I-IV. Respir Physiol Neurobiol. 2012;181(3):351-358. doi:10.1016/j.resp.2012.03.014

18. Kern L, Condrau S, Baty F, et al. Oxygen kinetics during 6-minute walk tests in patients with cardiovascular and pulmonary disease. BMC Pulm Med. 2014;14(1):167. doi:10.1186/1471-2466-14-167

19. Van Gestel AJR, Baty F, Rausch-Osthof AK, Brutsche MH. Cardiopulmonary and gas-exchange responses during the six-minute walk test in patients with chronic obstructive pulmonary disease. Respiration. 2014;88(4):307-314. doi:10.1159/000365997

20. Morita AA, Silva LKO, Bisca GW, et al. Heart rate recovery, physical activity level, and functional status in subjects with COPD. Respir Care. 2018;63(8):1002-1008. doi:10.4187/respcare.05918

21. Simões RP, Bonjorno JC Jr, Beltrame T, Catai AM, Arena R, BorghiSilva A. Slower heart rate and oxygen consumption kinetic responses in the on- and off-transient during a discontinuous incremental exercise: effects of aging. Braz J Phys Ther. 2013;17(1):69-76. doi:10.1590/S1413-35552012005000056

22. Cole CR, Blackstone EH, Pashkow FJ, Snader CE, Lauer MS. Heart-rate recovery immediately after exercise as a predictor of mortality. $N$ Engl J Med. 1999;341(18):1351-1357. doi:10.1056/NEJM199910283411804

23. Chiappa GR, Borghi-Silva A, Ferreira LF, et al. Kinetics of muscle deoxygenation are accelerated at the onset of heavy-intensity exercise in patients with COPD: relationship to central cardiovascular dynamics. J Appl Physiol. 2008;104(5):1341-1350. doi:10.1152/ japplphysiol.01364.2007

24. Furlanetto KC, Donária L, Schneider LP, et al. Sedentary behavior is an independent predictor of mortality in subjects with COPD. Respir Care. 2017;62(5):579-587. doi:10.4187/respcare.05306

25. Kyle UG, Bosaeus I, De Lorenzo AD, et al. Bioelectrical impedance analysis_part II: utilization in clinical practice. Clin Nutr. 2004;23 (6):1430-1453. doi:10.1016/j.clnu.2004.09.012

26. Miller MR, Hankinson J, Brusasco V, et al. Standardisation of spirometry. Eur Respir J. 2005;26(2):319-338. doi:10.1183/ 09031936.05.00034805

27. Lang RM, Badano LP, Tsang W, et al. EAE/ASE recommendations for image acquisition and display using three-dimensional echocardiography. Eur Heart J Cardiovasc Imaging. 2012;13 (1):1-46. doi:10.1093/ehjci/jer316
28. Silva GPF, Da, Morano MTAP, Viana CMS, Magalhaes CB, de Pereira EDB A. Portuguese-language version of the COPD assessment test: validation for use in Brazil. J Bras Pneumol. 2013;39 (4):402-408. doi:10.1590/S1806-37132013000400002

29. Coutinho-Myrrha MA, Dias RC, Fernandes AA, et al. Duke activity status index for cardiovascular diseases: validation of the Portuguese translation. Arq Bras Cardiol. 2014;102(4):383-390. doi:10.5935/ abc. 20140031

30. HÄRKÖNEN R, PIIRTOMAA M, ALARANTA H. Grip strength and hand position of the dynamometer in 204 Finnish adults. J Hand Surg Am. 1993;18(1):129-132. doi:10.1016/0266-7681(93)90212-X

31. Waldo BR. Grip strength testing.pdf. Strength Cond. 1996;18 (5):32-35. doi:10.1519/1073-6840(1996)018<0032:GST >2.3.CO;2

32. ATS Committee on Proficiency Standards for Clinical Pulmonary Function Laboratories. American thoracic society ATS statement: guidelines for the six-minute walk test. Am J Respir Crit Care Med. 2002;166:111-117. doi:10.1164/rccm.166/1/111

33. Borg GAV. Psychophysical bases of perceived exertion. Med Sci Sport Exer. 1982;14(5):377-381. doi:10.1249/00005768-198205000-00012

34. She J, Nakamura H, Makino K, Ohyama Y, Hashimoto H. Selection of suitable maximum-heart-rate formulas for use with karvonen formula to calculate exercise intensity. Int J Autom Comput. 2015;12 (1):62-69. doi:10.1007/s11633-014-0824-3

35. Beltrame T, Rodrigo V, Hughson RL. Sex differences in the oxygen delivery, extraction, and uptake during moderate-walking exercise transition. Appl Physiol Nutr Metab. 2017;42(9):994-1000. doi:10.1139/apnm-2017-0097

36. Hughson RL, Morrissey M. Delayed kinetics of respiratory gas exchange in the transition from prior exercise. J Appl Physiol Respir Environ Exerc Physiol. 1982;52(4):921-929. doi:10.1152/ japp1.1982.52.4.921

37. Fawkner SG, Armstrong N, Potter CR, Welsman JR. Oxygen uptake kinetics in children and adults after the onset of moderate-intensity exercise. J Sports Sci. 2002;20(4):319-326. doi:10.1080/026404102 753576099

38. Taylor R. Interpretation of the correlation coefficient: a basic review. J Diagn Med Sonogr. 1990;6(1):35-39. doi:10.1177/87564793900 0600106

39. Maltais F, Jobin J, Sullivan MJ, et al. Metabolic and hemodynamic responses of lower limb during exercise in patients with COPD. $J$ Appl Physiol. 1998;84(5):1573-1580. doi:10.1152/jappl.1998.84.5.1573

40. Debigaré R, Côté $\mathrm{CH}$, Maltais F. Peripheral muscle wasting in chronic obstructive pulmonary disease. Am J Respir Crit Care Med. 2001;164(16):1712-1717. doi:10.1164/rccm2104035

41. Casaburi R. Skeletal muscle function in COPD. Chest. 2000;117 (5):267S-271S. doi:10.1378/chest.117.5 suppl 1.267S-a

42. Calik-Kutukcu E, Savci S, Saglam M, et al. A comparison of muscle strength and endurance, exercise capacity, fatigue perception and quality of life in patients with chronic obstructive pulmonary disease and healthy subjects: a cross-sectional study. BMC Pulm Med. 2014;14(1):1-10. doi:10.1186/1471-2466-14-6

43. Zanoria SJT, Zuwallack R. Directly measured physical activity as a predictor of hospitalizations in patients with chronic obstructive pulmonary disease. Chron Respir Dis. 2013;10(4):207-213. doi:10.1177/1479972313505880

44. Andrianopoulos V, Wouters EFM, Pinto-Plata VM, et al. Prognostic value of variables derived from the six-minute walk test in patients with COPD: results from the ECLIPSE study. Respir Med. 2015;109 (9):1138-1146. doi:10.1016/j.rmed.2015.06.013

45. Pitta F, Breyer MK, Hernandes NA, et al. Comparison of daily physical activity between COPD patients from Central Europe and South America. Respir Med. 2009;103(3):421-426. doi:10.1016/j.rmed.2008.09.019

46. Hernandes NA, Teixeira D de C, Probst VS, Brunetto AF, Ramos EMC, Pitta F. Perfil do nível de atividade física na vida diária de pacientes portadores de DPOC no Brasil. J Bras Pneumol. 2009;35(10):949-956. doi:10.1590/s1806-37132009001000002 
47. Wasserman K, Whipp BJ. Exercise physiology in health and disease. $A m$ Rev Respir Dis. 1975;112(2):219-249. doi:10.1164/arrd.1975.112.2.219

48. Herdy AH, Caixeta A. Brazilian cardiorespiratory fitness classification based on maximum oxygen consumption. Arq Bras Cardiol. 2016;106(5):389-395. doi:10.5935/abc.20160070

49. Bohannon RW, Peolsson A, Massy-Westropp N, Desrosiers J, BearLehman J. Reference values for adult grip strength measured with a jamar dynamometer: a descriptive meta-analysis. Physiotherapy. 2006;92(1):11-15. doi:10.1016/j.physio.2005.05.003

50. Vilaró J, Resqueti VR, Fregonezi GAF. Clinical assessment of exercise capacity in patients with chronic obstructive pulmonary disease. Rev Bras Fisioter. 2008;12(4):249-259.

51. Dias Novaes R, Silva de Miranda A, de Oliveira Silva J, Vasconcelos Fonseca Tavares B, Zuniga Dourado V, Dourado VZ, Equações de referência para a predição da força de preensão manual em brasileiros de meia idade e idosos reference equations for predicting of handgrip strength in Brazilian middle-aged and elderly subjects ENDEREÇO PARA CORRESPONDÊNCIA. Fisioter Pesq. 2009;16(3):217-239. doi:10.1590/S1809-29502009000300005

52. Yorke AM, Curtis AB, Shoemaker M, Vangsnes E. Grip strength values stratified by age, gender, and chronic disease status in adults aged 50 years and older. J Geriatr Phys Ther. 2015;38(3):115-121. doi:10.1519/JPT.0000000000000037
53. Marino DM, Marrara KT, Ike D, De Oliveira AD, Jamami M, Di Lorenzo VAP. Study of peripheral muscle strength and severity indexes in individuals with chronic obstructive pulmonary disease. Physiother Res Int. 2010;15(3):135. doi:10.1002/pri.454

54. Puhan MA, Siebeling L, Zoller M, Muggensturm P, Ter RG. Simple functional performance tests and mortality in COPD. Eur Respir $J$. 2013;42(4):956-963. doi:10.1183/09031936.00131612

55. Silva da ALG, Garmatz E, Goulart C da L, LL C, Cardoso DM, Paiva DN. Handgrip and functional capacity in chronic obstructive pulmonary disease patients. Fisioter Mov. 2017;30(3):501-507. doi:10.1590/1980-5918.030.003.ao08

56. Solway S, Brooks D, Lacasse Y, Thomas S. A qualitative systematic overview of the measurement properties of functional walk tests used in the cardiorespiratory domain. Chest. 2001;119(1):256-270. doi:10.1378/chest.119.1.256

57. Bonança AM. Cinética de recuperação das respostas metabólicas e cardiovasculares após exercício de carga constante em pacientes com IC com e sem DPOC associada: efeitos da ventilação não invasiva. Federal University of Sao Carlos; 2018. https://repositorio. ufscar.br/handle/ufscar/10621. Accessed July 24, 2020.

\section{Publish your work in this journal}

The International Journal of COPD is an international, peer-reviewed journal of therapeutics and pharmacology focusing on concise rapid reporting of clinical studies and reviews in COPD. Special focus is given to the pathophysiological processes underlying the disease, intervention programs, patient focused education, and self management protocols. This journal is indexed on PubMed Central, MedLine and CAS. The manuscript management system is completely online and includes a very quick and fair peer-review system, which is all easy to use. Visit http://www.dovepress.com/testimonials.php to read real quotes from published authors. 